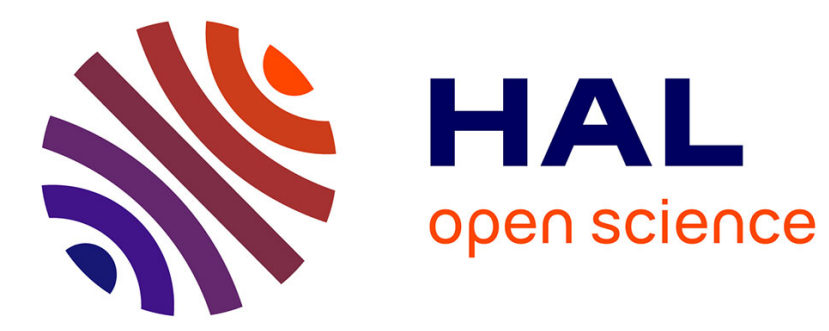

\title{
Mineral sequestration of CO2 by aqueous carbonation of coal combustion fly-ash
}

\author{
G. Montes-Hernandez, R. Perez-Lopez, F. Renard, J.-M. Nieto, L. Charlet
}

\section{To cite this version:}

G. Montes-Hernandez, R. Perez-Lopez, F. Renard, J.-M. Nieto, L. Charlet. Mineral sequestration of CO2 by aqueous carbonation of coal combustion fly-ash. Journal of Hazardous Materials, 2008, 161 (2-3), pp.1347 à 1354. 10.1016/j.jhazmat.2008.04.104 . insu-00351921

\section{HAL Id: insu-00351921 https://hal-insu.archives-ouvertes.fr/insu-00351921}

Submitted on 12 Jan 2009

HAL is a multi-disciplinary open access archive for the deposit and dissemination of scientific research documents, whether they are published or not. The documents may come from teaching and research institutions in France or abroad, or from public or private research centers.
L'archive ouverte pluridisciplinaire $\mathbf{H A L}$, est destinée au dépôt et à la diffusion de documents scientifiques de niveau recherche, publiés ou non, émanant des établissements d'enseignement et de recherche français ou étrangers, des laboratoires publics ou privés. 


\title{
Mineral sequestration of $\mathrm{CO}_{2}$ by aqueous carbonation of
}

\section{coal combustion fly-ash}

(1)

\author{
G. Montes-Hernandez ${ }^{*}$, a, R. Pérez-López ${ }^{\text {a, b }}$, F. Renard ${ }^{\text {a, c }}$, J.M. Nieto ${ }^{\text {b }}$, L. Charlet ${ }^{\text {a }}$
}

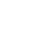

${ }^{a}$ LGIT, CNRS-OSUG-UJF, Université Joseph Fourier, Maison de Géosciences, BP 53, 38041

Grenoble Cedex, France

b Department of Geology, University of Huelva, Campus 'El Carmen', 21071, Huelva, Spain

${ }^{\mathrm{c}}$ Physics of Geological Processes, University of Oslo, Norway

${ }^{*}$ Corresponding author: German Montes-Hernandez 


\section{Abstract}

The increasing $\mathrm{CO}_{2}$ concentration in the Earth's atmosphere, mainly caused by fossil fuel combustion, has led to concerns about global warming. A technology that could possibly contribute to reducing carbon dioxide emissions is the in-situ mineral sequestration (long term geological storage) or the ex-situ mineral sequestration (controlled industrial reactors) of $\mathrm{CO}_{2}$. In the present study, we propose to use coal combustion fly-ash, an industrial waste that contains about 4.1 wt.\% of lime $(\mathrm{CaO})$, to sequester carbon dioxide by aqueous carbonation. The carbonation reaction was carried out in two successive chemical reactions, firstly the irreversible hydration of lime:

$$
\mathrm{CaO}+\mathrm{H}_{2} \mathrm{O} \rightarrow \mathrm{Ca}(\mathrm{OH})_{2}
$$

secondly, the spontaneous carbonation of calcium hydroxide suspension:

$$
\mathrm{Ca}(\mathrm{OH})_{2}+\mathrm{CO}_{2} \rightarrow \mathrm{CaCO}_{3}+\mathrm{H}_{2} \mathrm{O}
$$

A high $\mathrm{CaO}-\mathrm{CaCO}_{3}$ chemical transformation (approximately $82 \%$ ) was estimated by mass balance after two hours of reaction at $30^{\circ} \mathrm{C}$. The carbonation of $\mathrm{CaO}$ was independent on the initial pressure of $\mathrm{CO}_{2}(10,20,30$ and 40 bar $)$ and it was slightly affected by the temperature of reaction $\left(30\right.$ and $\left.60{ }^{\circ} \mathrm{C}\right)$. The precipitate calcium carbonate was characterized by isolated micrometric particles and micrometric agglomerates of calcite (SEM observations). In addition, the calcite precipitation and lime dissolution were confirmed by comparison of $\mathrm{X}$ ray diffraction spectra. This experimental study demonstrates that one ton of fly-ash could sequester up to $26 \mathrm{~kg}$ of $\mathrm{CO}_{2}$. This confirms the possibility to use the alkaline liquid-solid waste for $\mathrm{CO}_{2}$ mitigation.

Keywords: Mineral sequestration of $\mathrm{CO}_{2}$; Fly-ash; Aqueous carbonation; Calcium oxide; Calcite 


\section{Introduction}

The global warming of Earth's near-surface, air and oceans in recent decades is a direct consequence of anthropogenic emission of greenhouse gases into the atmosphere such as $\mathrm{CO}_{2}, \mathrm{CH}_{4}, \mathrm{~N}_{2} \mathrm{O}$ and $\mathrm{CFCs}(1)$. The $\mathrm{CO}_{2}$ emissions contribute approximately $60 \%$ to this climate change. From the time of the industrial revolution that started the 1860 's, $75 \%$ of $\mathrm{CO}_{2}$ emissions discharged into the atmosphere are caused by the burning of fossil fuels $(26.4 \pm 1.1$ $\mathrm{Gt} \mathrm{CO}_{2} \mathrm{yr}^{-1}$ for the 2000-2005 period), and the remaining $25 \%$ by land use change (1). Although oceans and terrestrial biosphere can take up high amounts of the $\mathrm{CO}_{2}$ emitted, about $45 \%$ remains in the atmosphere as stable specie that may stay for many thousands of years (1). The continuous increase of atmospheric $\mathrm{CO}_{2}$ might lead to stress on drinking water availability, species extinction, melting of ice sheets and coastal flooding (2).

Motivated by concerns about climate change, technical solutions are searched to minimize these harmful consequences. The main actions include: (I) the increase of the efficiency of energy conversion, (II) the reduction of energy demand and (III) the use of carbon free energy sources (nuclear, solar, wind, geothermal and biomass energy) (3). However, fossil fuels account for $85 \%$ of world energy needs in the current energy system, and hence, rapid variations of the demand or the prices in the market may seriously harm the global economy. Likewise, the use of fossil fuels will likely continue at the next decades owing to both its low cost and high availability.

An alternative to reduce the $\mathrm{CO}_{2}$ emission without modifying the energy production system is the retention or sequestration of carbon dioxide in stable geological reservoirs (4-7). Such a strategy, so-called geological carbon sequestration, consists of capturing gaseous $\mathrm{CO}_{2}$ from emissions sources and injecting it as a supercritical fluid in terrestrial reservoirs, such as saline aquifers, depleted oil and gas fields or deep coal seams. In geological reservoirs, the supercritical $\mathrm{CO}_{2}$ could be retained by stratigraphic or structural trapping (physical isolation), 
1 solubility trapping (dissolved in the aqueous phase) and/or hydrodynamic trapping (associated

2 to long residence time of dissolved $\mathrm{CO}_{2}$-bearing fluids in aquifers). However, the main

3 scientific concerns inquiring the geological carbon sequestration applicability are the high

4 pressure and temperature variations caused by the large $\mathrm{CO}_{2}$ accumulation on the reservoirs.

5 These thermodynamic variations could exert forces that diminish the reservoir confinement

6 due to the formation of cracks and faults either in reservoir itself or in the cap rocks.

7 Moreover, the $\mathrm{CO}_{2}$ dissolution into the pore water and the consecutive carbonic acid

8 formation can result in the dissolution of several minerals (mainly carbonate, oxides and hydroxide minerals) affecting the long-term confinement properties of the reservoirs (8).

In terrestrial reservoirs, the $\mathrm{CO}_{2}$ pressure can decrease in the long term as a consequence of another retention mechanism: mineral trapping or mineralogical carbon sequestration. The stored $\mathrm{CO}_{2}$ may transform to stable carbonate minerals by reactions with aqueous ions (mainly calcium, magnesium and iron) resulting from silicate weathering (9-12). Although this mechanism favours the permanent $\mathrm{CO}_{2}$ sequestration, it is expected to be slow in geological formation (hundreds of years) due to the slow kinetics of silicate mineral dissolution and carbonate mineral precipitation. However, mineralogical carbon sequestration could contribute significantly to $\mathrm{CO}_{2}$ sequestration in the proximity of the emission source, without the need of storing the gas into a geological reservoir.

Soong et al. (13) proposed the use of mineralogical carbon sequestration in controlled reactors as a viable approach to reduce $\mathrm{CO}_{2}$ emissions into the atmosphere using by-products from coal combustion in power plants (fly-ash) and oil and gas production (brine solutions). Brine solutions act as calcium and magnesium source favouring the $\mathrm{CO}_{2}$ retention by carbonate precipitation. Fly-ash was used to increase the $\mathrm{pH}$ level of the reactant brine and also as an additional source of calcium to enhance reaction efficiency for the carbonation process. 
Coal combustion in power plants provides approximately $40 \%$ of world electricity generation. At present, the coal reserves are estimated around 900 billion ton (14). Considering that coal consumption reached 5 billion tonnes in 2003, coal-energy production will continue, and even increase, in the next centuries due to the energy demand for industrial and domestic uses (15). Therefore, the continuous building of power plants is envisaged to hold this energy production system. This may cause serious disruption to the global climate since each $500 \mathrm{MW}$ coal power plant emits about 3 million tonnes of $\mathrm{CO}_{2}$ per year. Likewise, the worldwide production of fly-ash, estimated currently at 600 million tonnes per year, will also increase exponentially in the near future. The main producers of fly-ashes are China, Russia and the United States of America.

Fly-ash material is used as cement raw material and as a partial replacement for cement in concrete. However, the global production of fly-ash exceeds their potential uses (16), and hence, it is considered a residual by-product. Only around a $30 \%$ of the total production is used as a construction material. At present, numerous investigations are focused on the search of new applications for this residue. Three main research lines use fly-ash: i) to synthesize zeolites to be applicable as filter material in water decontamination and gas retention $(17,18)$, ii) as an effective technique in metal retention processes in contaminated soils $(19,20)$ and, iii) for the treatment of mining wastes producers of acid mine drainage $(21,22)$. Although Soong et al. (13) propose the use of fly ash to sequester $\mathrm{CO}_{2}$, brine solutions were the main agent acting in the carbonation process. Moreover, these authors do not calculate the amount of $\mathrm{CO}_{2}$ sequestered during the process.

The objective of integrated waste management is the search for sustainable development, i.e. to balance the fulfilment of human needs with the protection of the natural environment in the present and indefinite future. With this in mind, the main aim of this work is precisely to quantify the $\mathrm{CO}_{2}$ amount that may be sequestered by calcite precipitation using fly-ash-water 
1 dispersion. This study is in our opinion especially attractive since the residual solid by-

2 products from power plants could be used to mitigate the residual gaseous wastes produced by

3 the same plants.

\section{Materials and methods}

\subsection{Fly-ash material}

The fly-ash used in the present study is a waste residue generated from coal combustion at Los Barrios power station, Cádiz, south Spain. It is a powder composed mainly of spherical microparticles collected from electrostatic precipitators located at the outlet of the chimney were combustion gasses are liberated into the atmosphere. Size distribution analysis indicates that the particles have a median diameter of $40 \mu \mathrm{m}$. The specific surface area is $0.63 \pm 0.022$ $\mathrm{m}^{2} \mathrm{~g}^{-1}$ determined by BET gas adsorption method (MICROMERITICS ASAP 2000 instrument). Mineral abundances are similar to those reported by Querol et al. (23), and show that fly-ash is composed of mullite (20.8 wt.\%), quartz (4.5\%), lime (4.1\%), anhydrite (1.3\%), K-feldspar $(2.5 \%)$, magnetite $(0.5 \%)$ and a chalco-aluminosilicate glass phase (66.4\%). The chemical composition measured by X-ray fluorescence (XRF, BRUKER PIONEER instrument) shows that Los Barrios fly-ash is a residue rich in $\mathrm{Si}\left(41.3\right.$ wt.\% $\left.\mathrm{SiO}_{2}\right)$, $\mathrm{Al}\left(27.5\right.$ wt.\% $\left.\mathrm{Al}_{2} \mathrm{O}_{3}\right), \mathrm{C}\left(16\right.$ wt.\% $\left.\mathrm{CO}_{2}\right)$, $\mathrm{Ca}(5$ wt.\% $\mathrm{CaO})$, and $\mathrm{Fe}\left(3.3\right.$ wt.\% $\left.\mathrm{Fe}_{2} \mathrm{O}_{3}\right)$ with minor elements (wt.\%): $\mathrm{Sr}(0.3 \%), \mathrm{Cl}(0.02 \%), \mathrm{Cr}(0.01 \%), \mathrm{Ni}(0.02 \%), \mathrm{Zn}(0.01 \%), \mathrm{V}$ (0.01\%), $\mathrm{Cu}(0.01 \%), \mathrm{Co}(0.01 \%)$ and $\mathrm{Sc}(0.003 \%)$. The presence of lime $(\mathrm{CaO}, 4.1 \mathrm{wt} \%)$ in fly-ash accounts for the high potential of both alkalinity and dioxide carbon sequestration as discussed below. 
2.2 $\mathrm{CO}_{2}$ sequestration experiments in a stirred reactor

One litre of high-purity water with electrical resistivity of $18.2 \mathrm{M} \Omega \mathrm{cm}$ and $100 \mathrm{~g}$ of fly-ash were placed in a titanium reactor (autoclave Parr with internal volume of two litres). The flyash particles were immediately dispersed by mechanical stirring (450 rpm). The dispersion (solution + solid particles) was then heated to 30 or $60^{\circ} \mathrm{C}$ using an oven specifically adapted to the reactor. When the dispersion temperature was reached, 10, 20, 30 or 40 bar of $\mathrm{CO}_{2}$ (provided by Linde Gas S.A.) was injected in the reactor (see Fig. 1). This was the initial pressure of $\mathrm{CO}_{2}$ which was equal to the total initial pressure in the system. Previous experiments showed that after two hours of reaction the pressure drop was close to the thermodynamic equilibrium in the system. For this reason, we considered a reaction time of two hours for all experiments in the present study.

Obviously, both the sorption-dissociation of $\mathrm{CO}_{2}$ in the solution and aqueous carbonation process produce a global pressure drop in the system, $P_{\text {global_pressure-drop. }}$ In order to estimate the pressure drop produced only by the process of $\mathrm{CaO}$ carbonation (noted $P_{\text {carbonation_pressure- }}$ drop), two complementary systems were proposed for each experiment. Firstly, the pressure drop $P_{\text {water_pressure-drop }}$ related to the sorption-dissociation of $\mathrm{CO}_{2}$ into pure water only was measured. Secondly, the pressure drop $P_{\text {Ca-rich_pressure-drop }}$ related to the sorption-dissociation of $\mathrm{CO}_{2}$ in a Ca-rich solution was measured independently. In this second experiment, a concentration of $1 \mathrm{~g} / \mathrm{L}$ of calcium was chosen, that represented the average concentration after fly-ash dispersion in water. These two experiments demonstrated that the Ca-concentration $(0-1 \mathrm{~g} / \mathrm{L})$ has no measurable effect on the sorption-dissociation of $\mathrm{CO}_{2}$ because the monitored pressure drop in pure water $P_{\text {water_pressure-drop }}$ was equivalent to the monitored pressure drop in

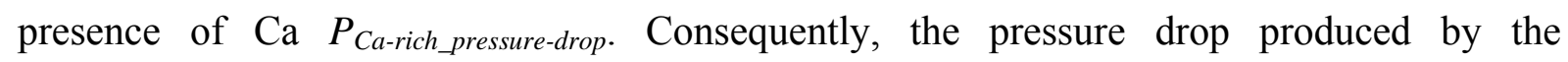
carbonation process of $\mathrm{CaO}$ was calculated by a simple pressure balance:

$P_{\text {carbonation_pressure-drop }}=P_{\text {global_pressure-drop }}-P_{\text {water_pressure-drop }}$ 
1 Under isothermal conditions, $P_{\text {global_pressure-drop }}$ and $P_{\text {water_pressure-drop }}$ are proportional to the

2 initial $\mathrm{CO}_{2}$ pressure.

3 At the end of the experiment, the reactor was removed from the heating system and was

4 immersed into cold water. The reaction cell was depressurized for 15 minutes during the

5 water cooling period. Then, water cooling at $30^{\circ} \mathrm{C}$ the reactor was disassembled, and the solid

6 product was separated by centrifugation (30 minutes at 12,000 rpm), decanting the

7 supernatant solutions. Finally, the solid product was dried directly in the centrifugation flasks

8 for $48 \mathrm{~h}$ at $65^{\circ} \mathrm{C}$. The supernatant solutions were filtered through a $0.2-\mu \mathrm{m}$ Teflon filter.

9 Adsorption on the filter and filter holder was considered negligible. The filtered solutions

10 were immediately acidified for measurement of [Ca], [Ni], $[\mathrm{Zn}],[\mathrm{Cu}]$ and $[\mathrm{Sr}]$ by Inductively

11 Coupled Plasma Atomic Emission Spectrometry (ICP-AES).

\subsection{Characterization of the solid phase}

The mineralogical characterization of the starting material and solid products was carried out by X-ray diffraction (XRD, powder method) using a D501 SIEMENS diffractometer. Working conditions were CoK $\alpha$ monochromatic radiation ( $\lambda=1.7902 \AA ̊), 37.5 \mathrm{~mA}$ and $40 \mathrm{kV}$. The experimental measurement parameters were $12 \mathrm{~s}$ counting time per $0.02^{\circ} 2 \theta$ step in the 5 $80^{\circ} 2 \theta$ range. The detection is performed by a kevex $\mathrm{Si}(\mathrm{Li})$ detector. Morphological analyses were also characterized by means of a scanning electron microscopy (SEM), with a JEOL JSM-5410 instrument, equipped with an energy dispersive system (EDS) for the chemical microanalysis. 
2

\section{Results and discussion}

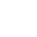

A previous investigation showed that the carbonation of calcium hydroxide suspension at high pressure of $\mathrm{CO}_{2}$ (initial $\mathrm{P}_{\mathrm{CO} 2}=55$ bar) and moderate and high temperature $\left(30\right.$ and $90^{\circ} \mathrm{C}$ ) is a potential method to synthesize fine particles of calcite (24). In addition, the reported results have important ecological implications for the ex-situ mineral sequestration of $\mathrm{CO}_{2}$ by alkaline liquid-solid waste such as fly-ash, bottom ash, $\mathrm{Ca} / \mathrm{Mg}$-rich silicates, alkaline waste water, etc. For this reason, the current study was focussed on the mineral sequestration of $\mathrm{CO}_{2}$ by aqueous carbonation of fly-ash. In the following sub-sections, the chemical reactions of $\mathrm{CO}_{2}$ sequestration by fly-ash and, the calculation of the sequestrated quantity of $\mathrm{CO}_{2}$ by calcite precipitation and kinetic modelling of sequestered $\mathrm{CO}_{2}$ in a fly-ash-water suspension are described and discussed.

\subsection{Chemical reactions of $\mathrm{CO}_{2}$ sequestration by fly-ash}

The SEM images of solid product (Figure 2), the comparison of x-ray diffraction spectra of the starting material and the solid product (Figure 3) and ICP-AES analysis in the solutions, suggest a simple reaction mechanism for $\mathrm{CO}_{2}$ mineral sequestration by fly-ash in two successive steps: firstly the irreversible hydration of calcium oxide or lime:

$\mathrm{CaO}+\mathrm{H}_{2} \mathrm{O} \rightarrow \mathrm{Ca}(\mathrm{OH})_{2}$

secondly, the spontaneous carbonation of calcium hydroxide suspension:

$\mathrm{Ca}(\mathrm{OH})_{2}+\mathrm{CO}_{2} \rightarrow \mathrm{CaCO}_{3}+\mathrm{H}_{2} \mathrm{O}$

The precipitate calcium carbonate is characterized by isolated micrometric particles and micrometric agglomerates of calcite (Figure 2). In addition, the calcite precipitation and lime (CaO) dissolution were confirmed by comparison of X-ray diffraction spectra (Figure 3). 
1 Finally, the chemical-element concentrations for $\mathrm{Ca}, \mathrm{Ni}, \mathrm{Zn}, \mathrm{Cu}$ and $\mathrm{Sr}$ in the solution after

2 two hours of fly-ash-pure water-carbon dioxide interactions suggest a preferential and rapid

3 dissolution of lime phase and possibly a slight dissolution of the glass phase $([\mathrm{Ca}] \approx$

$4800 \mathrm{mg} / \mathrm{L}$ ) (22). Concerning, the trace elements (contained initially in the fly-ash) only the

5 strontium was detected in the solution by ICP-AES $([\mathrm{Sr}] \approx 8 \mathrm{mg} / \mathrm{L})$. Consequently, the

6 concentrations of $\mathrm{Ni}, \mathrm{Zn}$ and $\mathrm{Cu}$ were considered to be smaller than $6 \mathrm{ppb}$ (detection limit).

7 This demonstrates that the fly-ash dispersion into pure water did not favour the liberation of toxic metallic ions after two hours of solid-fluid interaction at moderate temperature. In fact, preliminary experiments show that the carbonation process favours the co-precipitation and/or incorporation of the dissolved impurities into the calcite crystallographic network.

3.2 The sequestered quantity of $\mathrm{CO}_{2}$ by calcite precipitation 
1 where, the $V$ is the reactor volume occupied with gas $(1 \mathrm{~L}), T$ is the temperature of reaction $2 \quad\left(\approx 303^{\circ} \mathrm{K}\right)$ and $R$ is the gas constant $\left(0.08314472 \mathrm{~L}\right.$. bar $\left./{ }^{\circ} \mathrm{K} . \mathrm{mol}\right)$. Using the measured value

$7 \quad C E=\frac{n_{\mathrm{CO} 2} * M_{\mathrm{CO} 2}}{\frac{w_{\mathrm{CaO}}}{M_{\mathrm{CaO}}} * M_{\mathrm{CO} 2}} * 100$ expression: mineral sequestration of $\mathrm{CO}_{2}$. $P_{\text {carbonation_pressure-drop }}=1.5$ bar, we calculated that 0.05954 mol of $\mathrm{CO}_{2}$ were consumed by the carbonation process. Taking into account reactions (2-3) and the fact that the fly-ash contains 4.1wt.\% of lime $(\mathrm{CaO})$, the carbonation efficiency $C E$ can be calculated by the following

where, $n_{\mathrm{CO} 2}$ is the mol number of consumed $\mathrm{CO}_{2}$, calculated by Eq. 4 (0.05954 mol), $M_{\mathrm{CO} 2}$ is the molar mass of $\mathrm{CO}_{2}(44.01 \mathrm{~g} / \mathrm{mol}), w_{\mathrm{CaO}}$ is the starting mass of $\mathrm{CaO}$ in the reactor $(4.1 \mathrm{~g})$ and $M_{C a O}$ is the molar mass of $\mathrm{CaO}(56.077 \mathrm{~g} / \mathrm{mol})$. The carbonation efficiency was equal to $82 \%$ after two hours of solid-fluid interactions at 30 and $60^{\circ} \mathrm{C}$.

Theoretically one ton of fly-ash containing $4.1 \%$ of lime could sequester $32.17 \mathrm{~kg}$ of $\mathrm{CO}_{2}$. With our experimental protocol, $26.19 \mathrm{~kg}$ of $\mathrm{CO}_{2}$ per ton of fly-ash could be successfully sequestered into stable calcite. Indeed, this is an attractive result concerning the ex-situ

\subsection{Kinetic modelling of sequestered $\mathrm{CO}_{2}$ in a fly-ash-water suspension}

The monitoring of the pressure drop for any controlled system under ideal gas conditions allows the kinetic modelling of sequestered $\mathrm{CO}_{2}$ after gas injection in a solid-liquid system (fly-ash-water dispersion for this study). This can be done using a simple correlation function, $n_{\text {total_CO2 }}=f(t)$, where $n_{\text {total_CO2 }}$ is the total mol quantity of sequestered $\mathrm{CO}_{2}$ in the fly-ash-water dispersion and $t$ is the time after gas injection.

Several kinetic models including first-order, pseudo-first-order, second-order, pseudo-secondorder, parabolic diffusion and power function kinetic expressions are reported in the literature 
1 for fitting the kinetic experimental or calculated data of the solid-fluid interaction processes.

2 For this study, the kinetic modelling concern the total sequestered quantity of $\mathrm{CO}_{2}$ in a fly-

$7 \quad \frac{d n_{\text {total_CO2,t }}}{d t}=k_{s}\left(n_{\text {total_CO2, } \max }-n_{\text {total_CO2,t }}\right)^{2}$ [mol].

$$
n_{\text {total_CO2,t }}=\frac{n_{\text {total_CO2, } \max } * t}{\left(\frac{1}{k_{s} * n_{\text {total_CO2, } \max }}\right)+t}
$$

$$
v_{0, s}=\frac{n_{\text {total_CO2,max }}}{t_{1 / 2}}=k_{s}\left(n_{\text {total }_{-} \mathrm{CO} 2, \max }\right)^{2}
$$

where $k_{s}$ is the rate constant of sequestered $\mathrm{CO}_{2}[1 / \mathrm{mol} \mathrm{s}]$ for a given initial pressure of $\mathrm{CO}_{2}$ in the system, $n_{\text {total_CO2,max }}$ is the maximum sequestered quantity of carbon dioxide at equilibrium [mol], $n_{\text {total_CO2,t }}$ is the sequestered quantity of carbon dioxide at any time, $t$,

The integrated form of Equation (6) for the boundary conditions $t=0$ to $t=t$ and $n_{\text {total_CO2,t}}=$ 0 to $n_{\text {total_CO2,t }}=n_{\text {total_CO2,t }}$ is represented by a hyperbolic equation:

In order to simplify the fitting of experimental-calculated data, we have defined the constant $t_{1 / 2}=1 / k_{s} * n_{\text {total_CO2,max }}$. Physically, $t_{1 / 2}$ represents the time after which half of the maximum sequestered quantity of carbon dioxide was reached and is called "half-sequestered $\mathrm{CO}_{2}$ time". It can be used to calculate the initial rate of sequestered $\mathrm{CO}_{2}, v_{0, s},[\mathrm{~mol} / \mathrm{s}]$.

The numerical fit of the experimental-calculated kinetic curve at 30 bar and $30^{\circ} \mathrm{C}\left(n_{\text {total_CO2,t }}\right.$ vs. $t$ ) using Eq. (7) is shown on Figure 5. The parameters $t_{1 / 2}$ and $n_{\text {total_CO2,max }}$ were estimated by applying a non-linear regression using the least-squares method. The initial rate of 
1 sequestered $\mathrm{CO}_{2}$ was calculated using Eq. $8\left(v_{0, \mathrm{~s}}=8.28 \times 10^{-4} \mathrm{~mol} / \mathrm{s}\right)$ at $30^{\circ} \mathrm{C}$. This value

2 indicates that the mass transfer of compressed $\mathrm{CO}_{2}$ in contact with solid-water dispersion is

3 higher that $\mathrm{CO}_{2}$ transfer at atmospheric conditions or at low pressure (25-26).

4

5

\subsection{Conclusion}

The results presented in this study showed that the ex-situ mineral sequestration of $\mathrm{CO}_{2}$ by aqueous carbonation of fly-ash could be an attractive and potential method to reduce the $\mathrm{CO}_{2}$ emission in the atmosphere from power plants. This experimental investigation demonstrated that one ton of fly-ash, an industrial waste that contains about $4.1 \mathrm{wt} . \%$ of lime $(\mathrm{CaO})$, could sequester up to $26 \mathrm{~kg}$ of $\mathrm{CO}_{2}$. This confirms the possibility to use the alkaline liquid-solid waste for $\mathrm{CO}_{2}$ mitigation. 


\section{Acknowledgements}

2

3 The authors are grateful to the National Research Agency, ANR (GeoCarbone4 CARBONATATION project) and the National Research Council (CNRS), France, for 5 providing a financial support for this work. Delphine Tisserand and Nicolas Geoffroy are 6 thanked for their technical assistance.

7 


\section{References}

(1) IPCC (Intergovernmental Panel on Climate Change). Climate Change 2007: The Physical Science Basis: Summary for Policymakers, 2007, http://ipccwg1.ucar.edu/wg1/Report/AR4WG1_Pub_SPM-v2.pdf

(2) IPCC (Intergovernmental Panel on Climate Change). Climate Change 2007: Climate Change Impacts, Adaptations, and Vulnerability, 2007, http://ipcc-wg2.org/index.html

(3) Schrag, D. P. Confronting the Climate-Energy Challenge. Elements 2007, 3, 171-178.

(4) Bachu, S. Sequestration of $\mathrm{CO}_{2}$ in geological media: criteria and approach for site selection in response to climate change. Energy Convers. Manage. 2000, 41, 953-970.

(5) Bachu, S. Sequestration of $\mathrm{CO}_{2}$ in geological media in response to climate change: road map for site selection using the transform of the geological space into the $\mathrm{CO}_{2}$ phase space. Energy Convers. Manage. 2002, 43, 87-102.

(6) Bachu, S; Adams, J. J. Sequestration of $\mathrm{CO}_{2}$ in geological media in response to climate change: capacity of deep saline aquifers to sequester $\mathrm{CO}_{2}$ in solution. Energy Convers. Manage. 2003, 44, 3151-3175.

(7) Friedmann, S. J. Geological Carbon Dioxide Sequestration. Elements 2007, 3, 179-184.

(8) Kharaka, Y. K.; Cole, D. R.; Hovorka, S. D.; Gunter, W. D.; Knauss, K. G.; Friefeld, B. M. Gas-water-rock interactions in Frio Formation following $\mathrm{CO}_{2}$ injection: Implications for the storage of greenhouse gases in sedimentary basins. Geology 2006, 34, 577-580.

(9) Gunter, W. D.; Perkins, E. H.; Hutcheon, I. Aquifer disposal of acid gases: modeling of water-rock reactions for trapping of acid wastes. Appl. Geochem. 2000, 15, 1085-1095.

(10) Kaszuba, J. P.; Janecky, D. R.; Snow, M. G. Carbon dioxide reaction processes in a model brine aquifer at $200{ }^{\circ} \mathrm{C}$ and 200 bars: implications for geologic sequestration of carbon. Appl. Geochem. 2003, 18, 1065-1080. 
1 (11) Kaszuba, J. P.; Janecky, D. R.; Snow, M. G. Experimental evaluation of mixed fluid reactions between supercritical carbon dioxide and $\mathrm{NaCl}$ brine: Relevance to the integrity of a geologic carbon repository. Chem. Geol. 2005, 217, 277-293.

(12) Giammar, D. E.; Bruant, R. G.; Peters, C. A. Forsterite dissolution and magnesite precipitation at conditions relevant for deep saline aquifer storage and sequestration of carbon dioxide. Chem. Geol. 2005, 217, 257-276.

(13) Soong, Y.; Fauth, D. L.; Howard, B. H.; Jones, J. R.; Harrison, D. K.; Goodman, A. L.; Gray, M. L.; Frommell, E. A. $\mathrm{CO}_{2}$ sequestration with brine solution and fly ashes. Energy Convers. Manage. 2006, 47, 1676-1685.

(14) BP (British Petroleum). Statistical Review of World Energy, 2006, http://www.bp.com/productlanding.do?categoryId=6848\&contentId=7033471

(15) Energy Information Administration. International Energy Annual. Department of Energy, Washington, DC, 2006, www.eia.doe.gov/iea

(16) Manz, O. E. Worldwide production of coal ash and utilization in concrete and other products. Fuel 1997, 76, 691-696.

(17) Querol, X.; Umaña, J. C.; Plana, F.; Alastuey, A.; Lopez-Soler, A.; Medinaceli, A.; Valero, A.; Domingo, M. J.; Garcia-Rojo, E. Synthesis of zeolites from fly ash at pilot plant scale. Examples of potential applications. Fuel 2001, 80, 857-865.

(18) Cama, J.; Ayora, C.; Querol, X.; Ganor, J. Dissolution kinetics of synthetic zeolite NaP1 and its implication to zeolite treatment of contaminated waters. Environ. Sci. Technol. 2005, 39, 4871-4877.

(19) Brake, S. S.; Jensen, R. R.; Mattox, J. M. Effects of coal fly ash amended soils on trace element uptake in plants. Environ. Geol. 2003, 45, 680-689.

(20) Dermatas, D.; Meng, X. Utilization of fly ash for stabilization/solidification of heavy metal contaminated soils. Eng. Geol. 2003, 70, 377-394. 
21

(21) Pérez-López, R.; Nieto, J. M.; Almodóvar, G. R. Immobilization of toxic elements in mine residues derived from the mining activities in the Iberian Pyrite Belt (SW Spain): laboratory experiments. Appl. Geochem. 2007, in press, doi:10.1016/j.apgeochem.2007.03.055.

(22) Pérez-López, R.; Cama, J.; Nieto, J. M.; Ayora, C. The iron-coating role on the oxidation kinetics of a pyritic sludge doped with fly ash. Geochim. Cosmochim. Acta 2007, 71, 1921-1934.

(23) Querol, X.; Umaña, J. C.; Alastuey, A.; Ayora, C.; Lopez-Soler, A; Plana, F. Extraction of soluble major and trace elements from fly ash in open and closed leaching systems. Fuel 2001, 80, 801-813.

(24) Montes-Hernandez, G., Renard, F., Geoffroy, N., Charlet, L., Pironon, J. Calcite precipitation from $\mathrm{CO}_{2}-\mathrm{H}_{2} \mathrm{O}-\mathrm{Ca}(\mathrm{OH})_{2}$ slurry under high pressure of $\mathrm{CO}_{2}$. J. Cryst. Growth 2007, 308, 228-236

(25) Akanksha, Pant, K. K., Srivastava, V. K. Mass transport correlation for $\mathrm{CO}_{2}$ absorption in aqueous monoethanolamine in a continuous film contactor. Chem. Eng. Process. 2007, doi:10.1016/j.cep.2007.02.008.

(26) Haubrock, J., Hogendoorn, J. A., Versteeg G. F. The applicability of activities in kinetic expressions: A more fundamental approach to represent the kinetics of the system $\mathrm{CO}_{2}$ $\mathrm{OH}^{-}$-salt in terms of activities. Chem. Eng. Sci. 2007, doi:10.1016/j.ces.2007.06.018. 


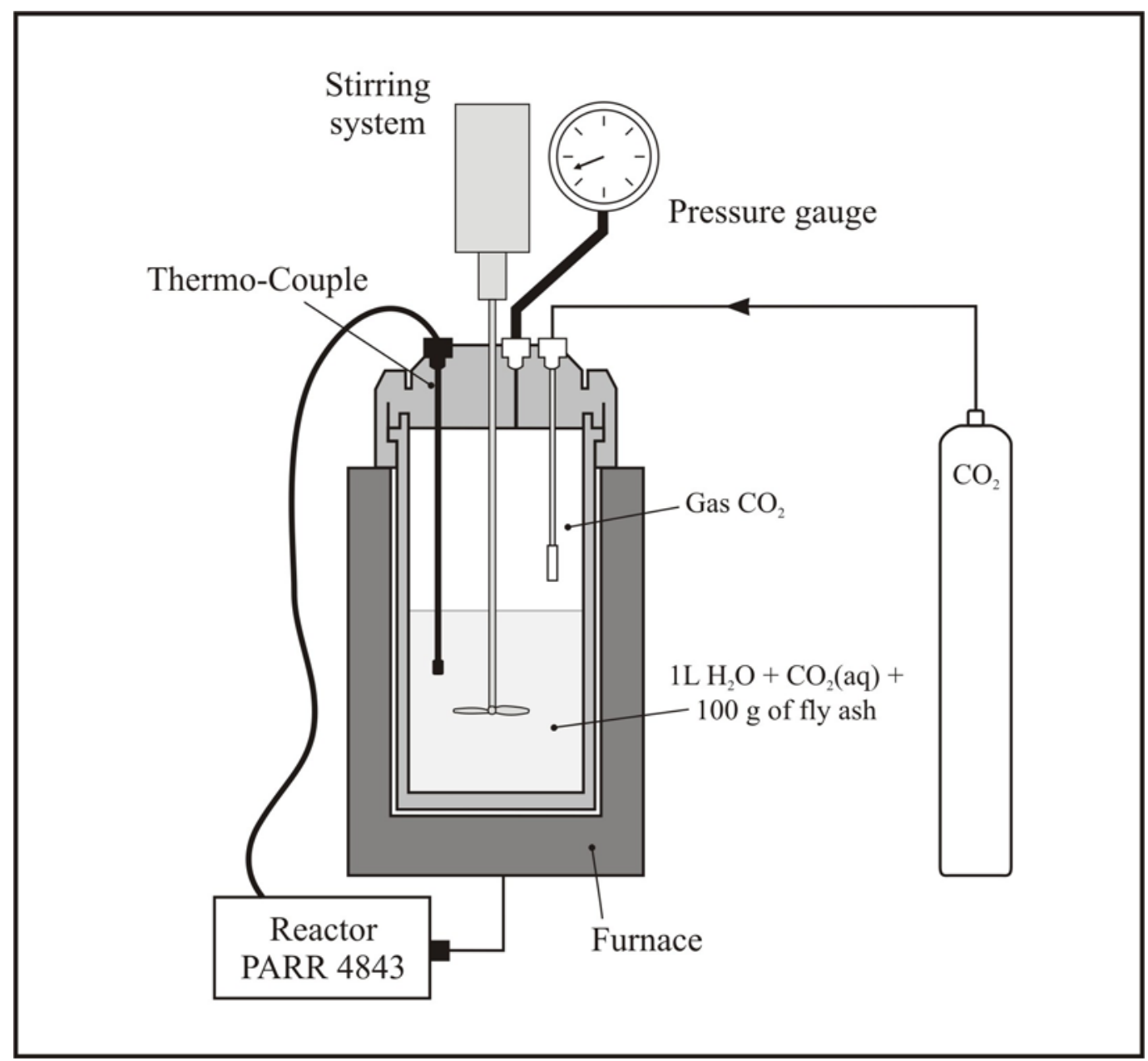

2

Figure 1. Schematic experimental system for mineral sequestration of $\mathrm{CO}_{2}$ by aqueous carbonation of fly-ash in a stirred reactor. 

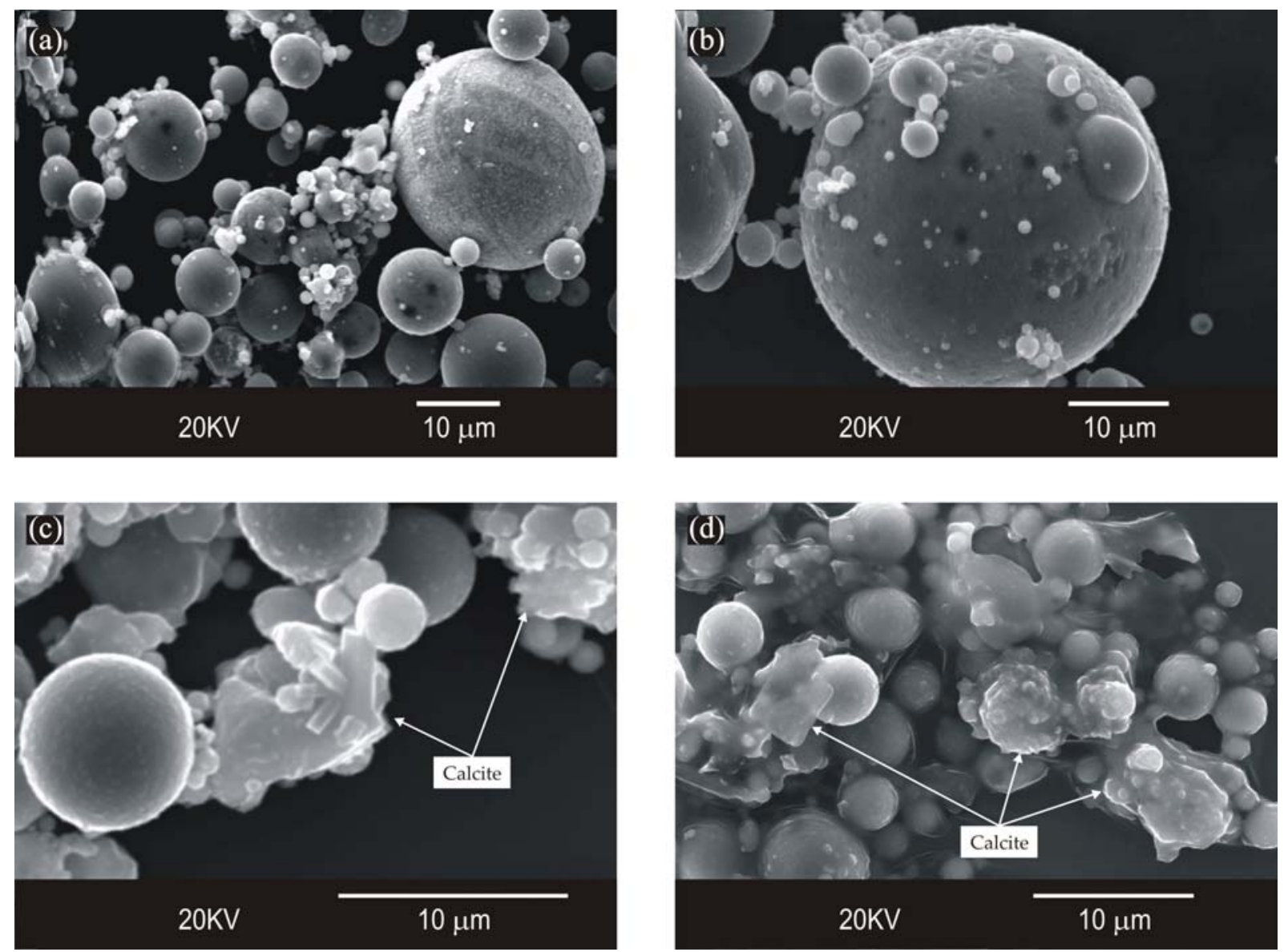

2

3

4

5

6

7

8

9

10

Figure 2. (a-b) SEM images of fly-ash before reaction. (c-d) Calcite particles precipitated during $\mathrm{CO}_{2}$ sequestration experiments. 


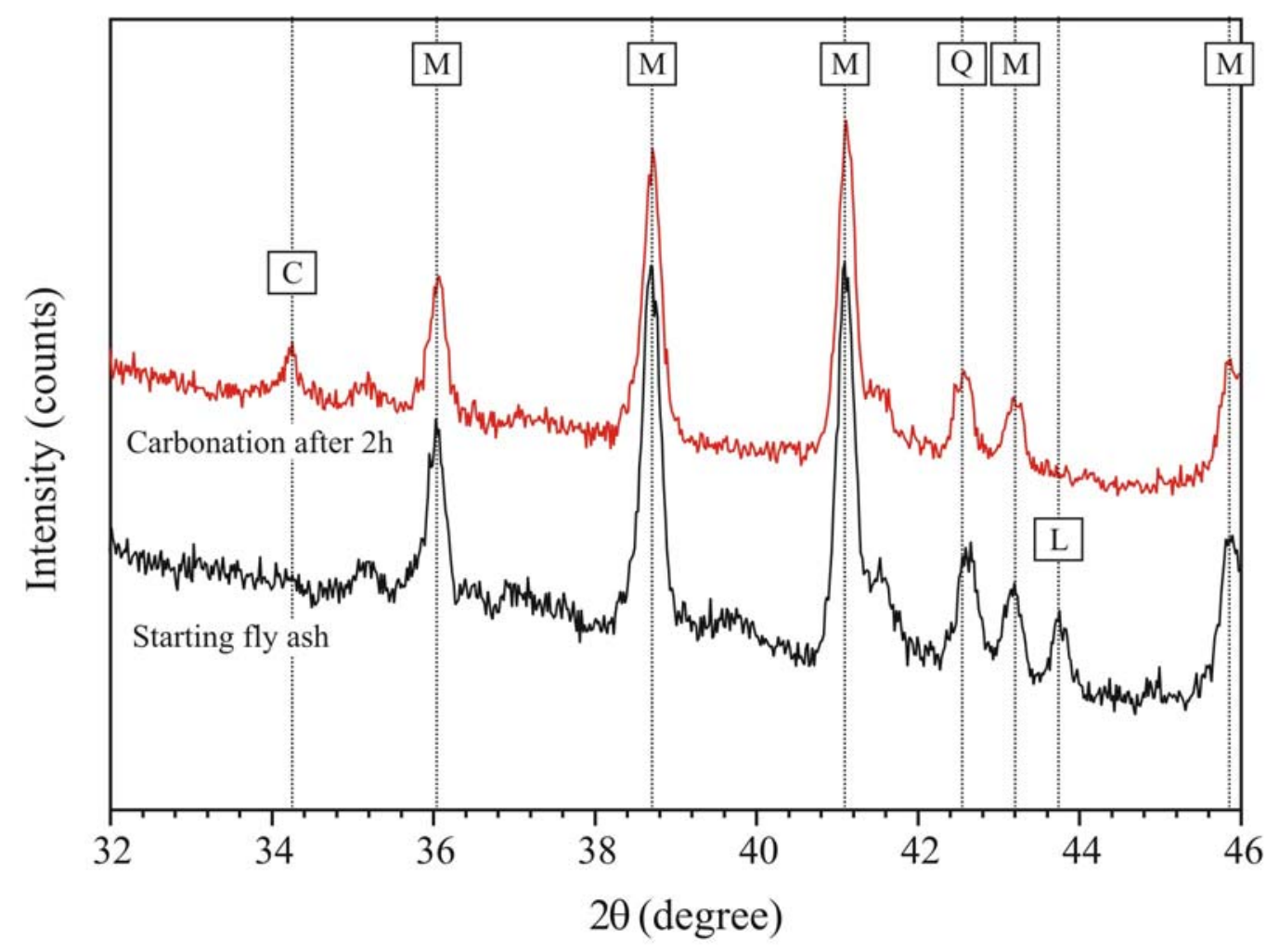

1

Figure 3. XRD spectra of starting fly-ash and solid products after carbonation during $2 \mathrm{~h}$. C: Calcite, M: Mullite, Q: Quartz, L: Lime. These spectra demonstrate the total consumption of lime and the production of calcite. 

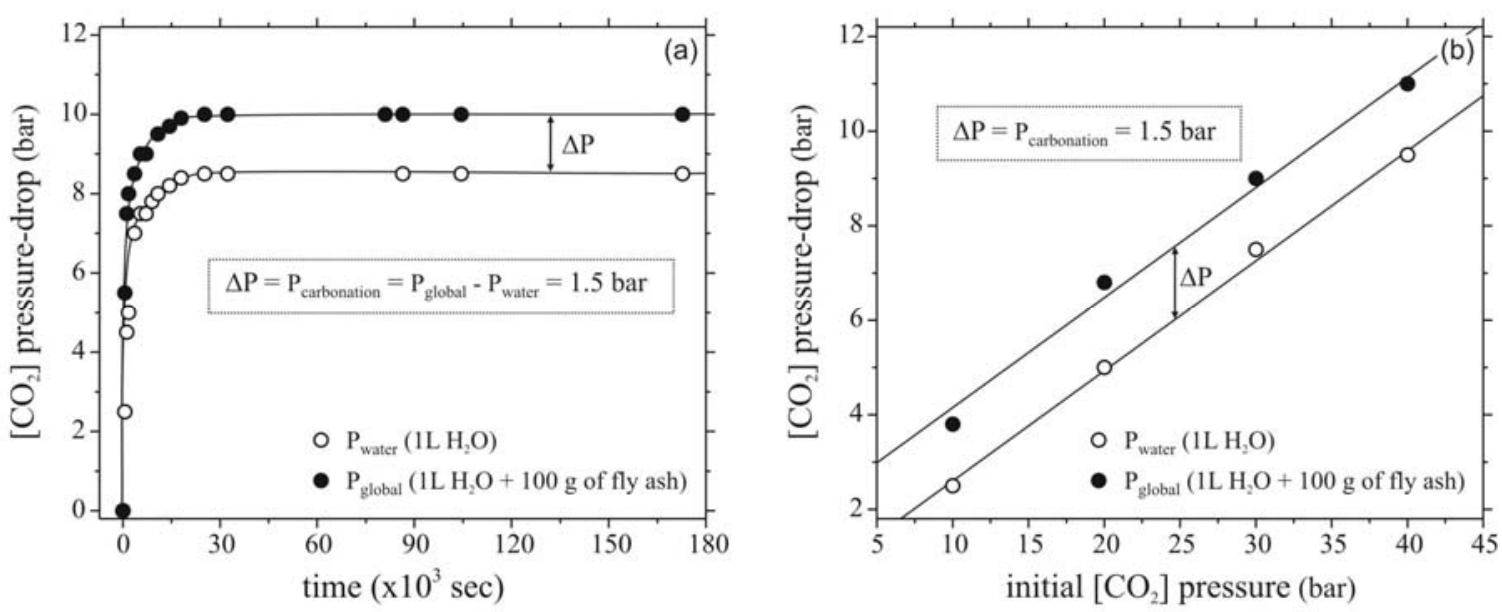

2

5

6

7

9

10

Figure 4. (a) Kinetic behaviour of pressure decrease in the reactor at $30^{\circ} \mathrm{C}$ and for 30 bar initial pressure of $\mathrm{CO}_{2}$. (b) Linear correlation between the pressure decrease at equilibrium and the initial pressure of $\mathrm{CO}_{2}$. 


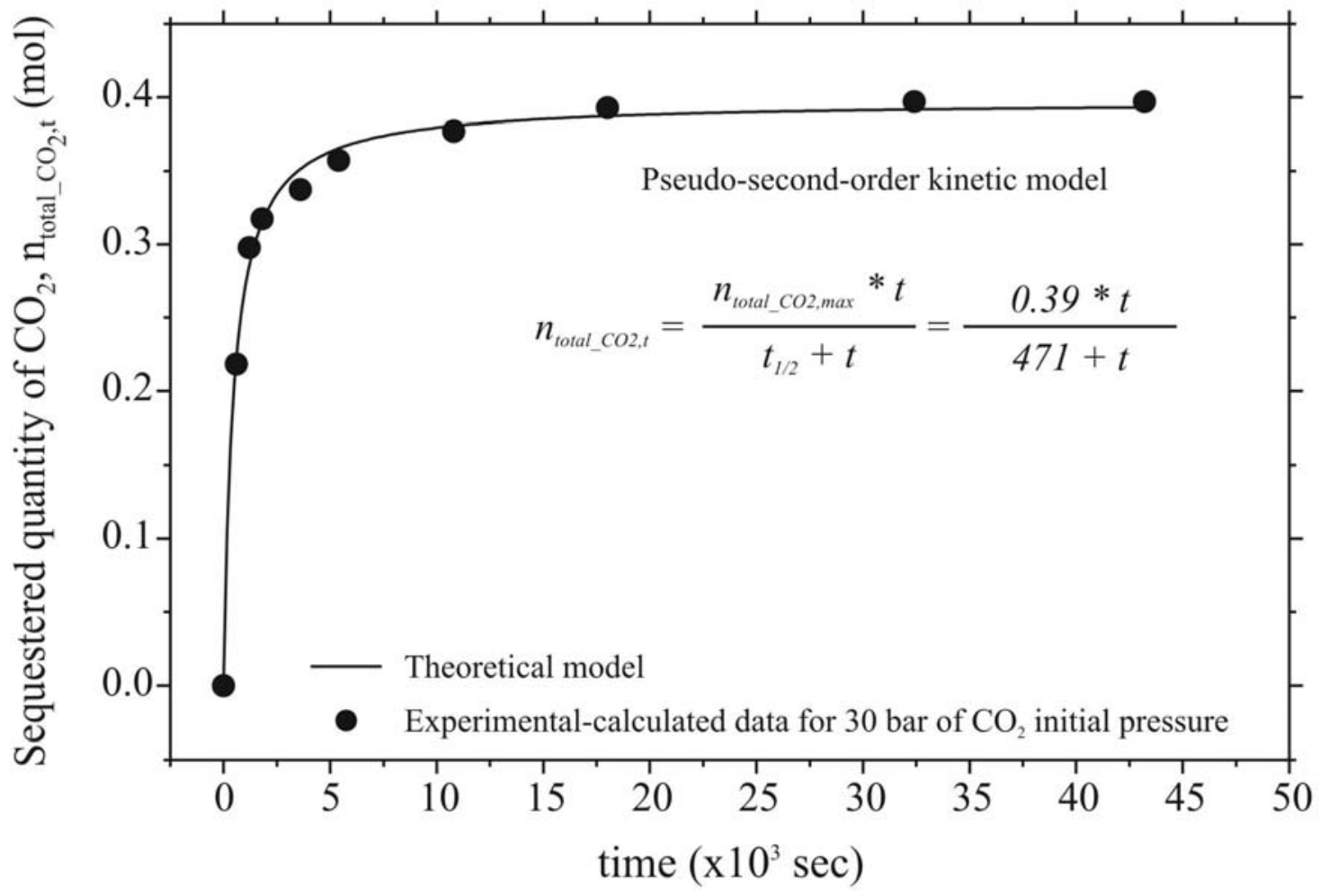

2

Figure 5. Kinetic modeling of sequestered $\mathrm{CO}_{2}$ in a fly-ash-water suspension for 30 bar initial pressure of $\mathrm{CO}_{2}$.

9 